Review

\title{
The Emerging Role of Cyclodextrin Metal-Organic Frameworks in Ostheotherapeutics
}

\author{
Susana Santos Braga ${ }^{1, *(1)}$ and Filipe A. Almeida Paz $2, *$ (i) \\ 1 LAQV-REQUIMTE, Department of Chemistry, University of Aveiro, 3810-193 Aveiro, Portugal \\ 2 CICECO-Aveiro Institute of Materials, Department of Chemistry, University of Aveiro, \\ 3810-193 Aveiro, Portugal \\ * Correspondence: sbraga@ua.pt (S.S.B.); filipe.paz@ua.pt (F.A.A.P.)
}

Citation: Braga, S.S.; Paz, F.A.A. The Emerging Role of Cyclodextrin Metal-Organic Frameworks in Ostheotherapeutics. Appl. Sci. 2022, 12, 1574. https://doi.org/10.3390/ app12031574

Academic Editor: Francis Verpoort

Received: 19 November 2021

Accepted: 28 January 2022

Published: 1 February 2022

Publisher's Note: MDPI stays neutral with regard to jurisdictional claims in published maps and institutional affiliations.

Copyright: (C) 2022 by the authors. Licensee MDPI, Basel, Switzerland. This article is an open access article distributed under the terms and conditions of the Creative Commons Attribution (CC BY) license (https:// creativecommons.org/licenses/by/ $4.0 /)$.

\begin{abstract}
Metal-Organic Frameworks (MOFs) are a class of coordination compounds with high versatility of design and a high loading ability. These properties have made them increasingly attractive for drug delivery, with research focusing mostly on the preparation of biocompatible MOFs. A suitable strategy is the use of cyclodextrins, cyclic oligosaccharides with excellent biosafety profiles. This review summarises the early steps taken in the application of cyclodextrin-coated and cyclodextrin-based MOFs in the treatment of bone-related diseases divided into three categories: cyclodextrin-coated MOFs, cyclodextrin-based MOFs and cross-linked derivatives of CD-MOFs. Applications in the delivery of bisphosphonates, osteoporotic regulating drugs and non-steroidal anti-inflammatory drugs, for osteoarthritis management, are highlighted. Lastly, the use of these materials in dentistry is exemplified with a recent report.
\end{abstract}

Keywords: $\gamma$-cyclodextrin; bisphosphonates; anti-inflammatory drugs; coordination compounds; surface functionalisation; cubic-shaped gel; sustained release; osteoarthritis; dental repair

\section{Introduction}

Metal-Organic Frameworks (MOFs) are coordination compounds typically described by a tri-dimensional network of bonds and are built of repeating units of organic molecules, also called linkers, coordinated to metal centres. The network may have only one type of metal or it may be comprised by a combination of different metals or clusters of metals [1] Similarly, the organic molecules that act as the metal-linking subunits may be more than one of a kind. The first structures presently recognised as MOFs date back to the 1960s [2]. However, the term Metal-Organic Framework was only coined by Omar Yaghi in the 1990s [1], a decade that witnessed the blooming of research in this field. Ever since the first reported structures, MOFs were known for their porosity, with early applications being in the field of gas sorption. Since then, many other properties were explored, with MOFs currently being materials of interest in the field of catalysis [3,4] and analytics [5-8], among many others.

A new class of biocompatible MOFs, or bioMOFs [9], is presently under steady growth for biological and drug delivery applications. The large dimensions of the pores of these materials make them able to load not only gases, as previously mentioned, but also a plethora of molecules, with highlight given to active pharmaceutical ingredients (APIs). In alternative, drug delivery with MOFs can be achieved by using APIs as their building blocks. This method offers the possibility of slowing down the release of the API, which no longer occurs as a mere result of diffusion (observed when APIs are inside the pore of the $\mathrm{MOF}$ ), being rather controlled by the rate of degradability of the API-metal coordination framework in a particular biological medium $[9,10]$.

The use of $\gamma$-cyclodextrin $\left(\gamma\right.$-CD), a highly symmetrical, octameric $\alpha_{1,4}$-linked Dglucose ring, as a building block for 'edible' MOFs was reported in 2010 by the group 
of Yaghi and Stoddart [11]. Naturally occurring cyclodextrins such as $\gamma-\mathrm{CD}$ and their smaller counterparts, $\alpha-C D$ and $\beta-C D$, having six and seven glucose units, respectively, are molecules of widespread use for the controlled delivery, solubilisation and shelf-life extension of active ingredients in the pharmaceutical, cosmetic and food industries [12-15]. Native cyclodextrins are 'generally recognised as safe' (GRAS) by the US Food and Drugs Administration (FDA) [16-18], they are approved as excipients by the European Medicines Agency (EMA) [19] and they have been classified as adequate additives for use in food by the Joint FAO/WHO Expert Committee on Food Additives (JECFA) [20-22]. MOFs built with $\gamma$-CD have an open porous framework that makes them able to support a high load. In tandem with their biocompatibility, this property has attracted much attention for the applications of $\gamma$-CD-MOFs in drug delivery. $\gamma$-CD-MOFs have been reported to include APIs such as lanzoprazole [23] and diazepam [24], and nutraceuticals such as curcumin [25] and folic acid [26].

In this work, we focus on the delivery of APIs for the treatment of bone-related disorders using MOFs that contain cyclodextrins. This is the first review on the applications of CD-MOFs in bone diseases, an emerging application for these materials. This paper is organised into two main sections. Section 2 describes the use of CDs in the coating layer on the surface of the MOFs and the subsequent use of these materials for the controlled release of bisphosphonates, drugs that regulate bone metabolism. Section 3 reports the use of $\gamma$-CD molecules as building units for $\gamma$-CD-MOFs. These can be used as-obtained as oral delivery systems for non-steroidal anti-inflammatory drugs, with application in osteoarthritis, or transformed by cross-linking into cubic-shaped gels (templated by the original $\gamma$-CD-MOF structure) for use in sustained release systems; an example is given of the use of these gels to deliver iodine, an antiseptic agent, in an animal periodontitis model.

\section{Cyclodextrin-Coated Metal-Organic Frameworks of the MIL Series}

The MIL series (where MIL is the acronym for Matériaux de l'Institut Lavoisier) comprises iron-based porous materials with carboxylic acids as the ligands. There are several families within the MIL series, with the MIL- 88 being characterised by the presence of a hexagonal unit cell in their structures, and by having the general formula $\left[\mathrm{Fe}_{3}(\mathrm{O}-\mathrm{L}-)_{3}\right]_{2}$, where the ligand (L) is fumaric acid in MIL-88A and 1,4-benzenedicarboxylic acid in MIL88B (Figure 1) [27,28].

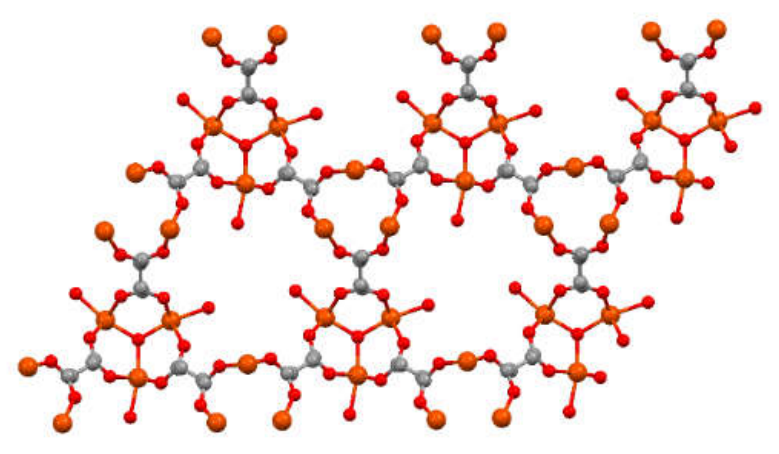

MIL-88A

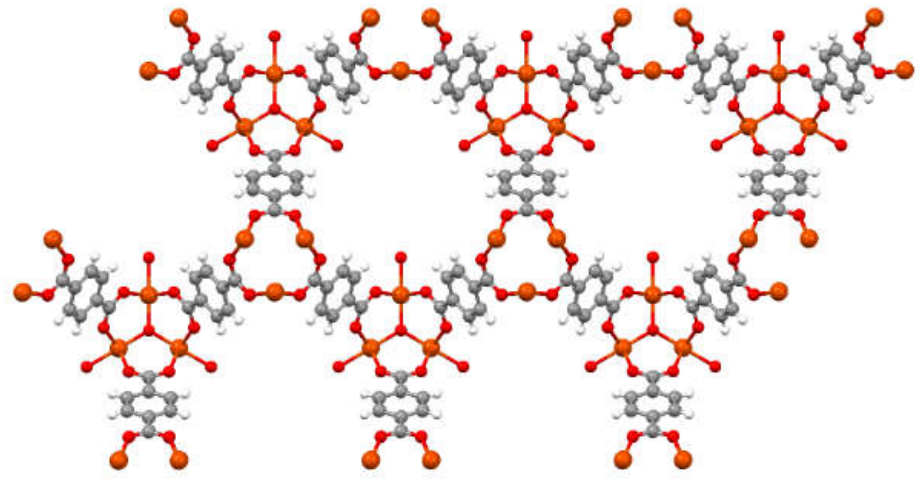

MIL-88B

Figure 1. Structural representation of MIL-88A (left) and MIL-88B (right), with carbon atoms represented in grey, oxygen atoms in red and iron atoms in orange; solvent molecules are omitted for clarity. Drawn with the software Mercury 3.5.1 (Copyright CCDC 2001-2014) from the atomic coordinates of MIL-88A (refcode FAVKAP) and of MIL-88B (refcode HAMXIG), available at the Cambridge Structural Database.

MIL-88A is fully biocompatible as it is composed of an organic acid that exists in the organism (being part of the Krebs cycle). Degradation to release the components of the 
MOF is the natural fate of bioMOFs; this way, MIL-88A degrades into its components under physiological conditions, releasing fumaric acid and iron [29].

Functionalisation of the surface of MOF particles with adequate organic molecules can contribute to fine-tune their properties or even to bring new biological functionalities. Functionalisation is useful to control the release of APIs carried inside the MOFs because it can reduce the size of the pores at the surface and, thus, limit diffusion to the external medium. Early steps in the functionalisation of MOFs with cyclodextrins were conducted on MIL-100, which is based on the ligand 1,3,5-benzenetricarboxilic acid [30]. Using phosphate derivatives of $\beta-C D$, it was possible to coat nanoparticles of MIL-100 in mild conditions (i.e., stirring in an aqueous medium at ambient temperature). The phosphate groups of the $\beta-\mathrm{CD}$ derivative coordinated with the available $\mathrm{Fe}^{\mathrm{III}}$ sites at the surface of MIL-100 crystallites without penetrating inside the MOF because they were too bulky to enter its pores. Coating the MOF with phosphate- $\beta$-CD was shown to help in stabilising it as a colloidal suspension in aqueous media without affecting the release rate of the API. Furthermore, $\beta$-CD-coated MIL-100 showed no in vitro cytotoxic effect on macrophages of the J774 cell line, which was interpreted as indicative of adequate biocompatibility.

Coating MIL-88B with $\beta$-CD followed a different approach. MIL-88B was prepared with a modified ligand having a free amine group, affording MIL-88B- $\mathrm{NH}_{2}$. This material was suspended in DMF and allowed to react with tosylated $\beta-C D$ in the presence of trimethylamine (all in anhydrous conditions and under inert atmosphere) [31]. Following, $\beta$-CD-coated MIL-88B was loaded with alendronate, one of the most commonly prescribed bisphosphonates for osteoporosis, and evaluated regarding the API release profile. Results showed an initial burst effect, which was attributed to the release of alendronate loaded at the surface of the MOF, followed by a slow and sustained diffusion-controlled release, corresponding to the molecules of alendronate carried inside the pores of the MOF. Notably, the sustained release profile was observed for as long as 28 days (the total time of observation in the study).

\section{Cyclodextrin-Based MOFs}

$\gamma$-CD-MOFs are comprised by $\gamma$-CD molecules as the organic linker and an alkaline metal, $\mathrm{Na}^{+}, \mathrm{K}^{+}, \mathrm{Rb}^{+}$or $\mathrm{Cs}^{+}$, as the metallic centre [11,32]. These materials are isostructural, with the following description being focused on the $\gamma$-CD-MOF with $\mathrm{K}^{+}$, the first to be isolated: a set of six $\gamma$-CD units forms a cubic-shaped arrangement, held together by four $\mathrm{K}^{+}$ions (Figure 2a). Each $\mathrm{K}^{+}$ion is eight-coordinated, embracing two primary $\mathrm{OH}$ groups and two glycosidic ring oxygen atoms, as well as four secondary $\mathrm{OH}$ groups. The centre of each $(\gamma-C D)_{6}$ cube comprises a quite large spherical pore with an average $1.7 \mathrm{~nm}$ diameter (Figure $2 \mathrm{~b}$ ). Pores are interconnected by a series of windows of roughly $0.78 \mathrm{~nm}$ in diameter, defined by the $\gamma-\mathrm{CD}$ tori at the faces of the cube (Figure 2c), to form a tri-dimensional framework with an estimated total pore volume of $54 \%$ [11,32]. 

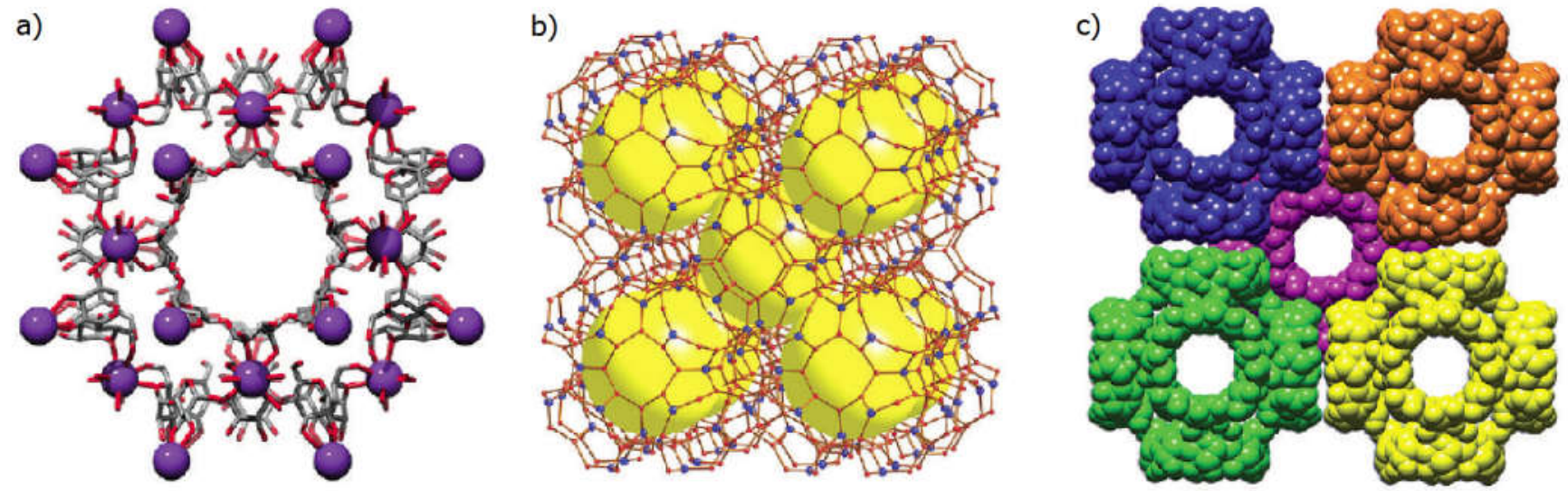

Figure 2. Representation of different aspects of the solid-state structure of the $\gamma$-CD-MOF with $\mathrm{K}^{+}$ions as metal centres: (a) one of the repeating $(\gamma-\mathrm{CD})_{6}$ units, each having a $1.7 \mathrm{~nm}$ diameter cavity, with $\gamma$-CD units depicted in the stick model and $\mathrm{K}^{+}$ions as purple spheres; (b) representation highlighting the porous network comprised of various large spherical cavities at the centres of the $(\gamma-C D)_{6}$ units, here depicted as large yellow spheres, while individual sugar units of the $\gamma-C D$ ring are depicted by red spheres and the $\mathrm{K}^{+}$ions by blue spheres; (c) space-filling representation of the extended body-centred cubic packing, with each separate $(\gamma-C D)_{6}$ units having a different colour to highlight the body-centred cubic packing arrangement. Reproduced with permission from Forgan et al. [32].

The unique geometry and porosity of $\gamma$-CD-MOFs translates into an exceptional loading ability, which has been used to incorporate a variety of anti-inflammatory and anti-septic agents useful in the contexts of osteoarthritis and dental repair, respectively. Details are given in the following subsections.

\section{1. $\gamma$-CD-MOFs Loaded with Anti-Inflammatory Agents for the Management of Osteoarthritis}

Osteoarthritis is a common age-related condition caused by wearing of the cartilage layer lining bone joints. The bone layer that lies beneath the affected cartilage usually suffers from sub-mineralisation and altered metabolism. Frequently, periosteal cells at the joint margin undergo excessive growth and cause the development of bony projections that bring pain to the patient $[33,34]$. Osteoclasts, the cells responsible for the removal and recycling of mineralised bone tissue, are involved in the development of osteoarthritis, being associated with pain generation by forming microchannels that connect the subchondral marrow spaces with the cartilage tissue at the edge of the articulation. Without any bone tissue left to retain them, pro-inflammatory cytokines and algesic factors can, thus, easily migrate from the synovial fluid where they are present, going through the microchannels, reaching the subchondral nerves and triggering pain [35]. The inflammation process is known to further contribute to the progression and persistence of the disease [36]. It is, thus, important to administer anti-inflammatory drugs, typically of the non-steroidal kind (NSAIDs), not only to alleviate the symptoms of the patient but to control the cycle of inflammation and cartilage destruction. Oral intake of NSAIDs, while universally recommended by international guidelines for patients with persistent symptoms, brings some risks, namely the occurrence of gastrointestinal discomfort as an adverse effect and possible cardiovascular events, such as stroke. Moreover, these risks are now known to be dose-dependent, thus increasing with high-dose or prolonged intake of NSAIDs [37].

$\gamma$-CD-MOFs are interesting carrier systems for NSAIDS because of their well-known high loading capacity in combination with their controlled release properties. Entrapment of diclofenac sodium into three different kinds of $\gamma$-CD-MOFs, two having traditional metal centres such as $\mathrm{Na}^{+}$and $\mathrm{K}^{+}$and an innovative third one prepared from $\gamma-\mathrm{CD}$ and $\mathrm{Fe}_{2} \mathrm{Cl}_{3}$, was reported [38]. Na- $\gamma$-CD-MOF, K- $\gamma$-CD-MOF and Fe- $\gamma$-CD-MOF all exhibited a high porosity, tallying well with previously reported values: the porous network was 
calculated to occupy $46 \%, 47 \%$ and $59 \%$ of the structure of $\mathrm{Na}-\gamma-\mathrm{CD}-\mathrm{MOF}, \mathrm{K}-\gamma-\mathrm{CD}-\mathrm{MOF}$ and Fe- $\gamma$-CD-MOF, respectively. The three $\gamma$-CD-MOFs were subsequently used to load high quantities of diclofenac sodium, with entrapment efficacies of $49 \pm 0.109 \%$ for Na$\gamma$-CD-MOF, $50 \pm 0.015 \%$ for K- $\gamma$-CD-MOF and $55 \pm 0.140 \%$ for Fe- $\gamma$-CD-MOF. All three $\gamma$-CD-MOFs exhibited sustained release properties for diclofenac sodium in a simulated GI tract experiment consisting of sequential immersion into three media: $2 \mathrm{~h}$ in $0.2 \mathrm{M} \mathrm{HCl}$ with $1.5 \%(w / v)$ polysorbate 80 (to simulate gastric fluid), $4 \mathrm{~h}$ in PBS $\mathrm{pH} 7.4$ (to simulate intestinal fluid) and $18 \mathrm{~h}$ in PBS with pH 6.8 (to simulate colonic fluid). While c.a. $73 \%$ of pure diclofenac sodium had dissolved after the first $30 \mathrm{~min}$ in simulated gastric fluid, slowly reaching $100 \%$ dissolution over 6.5 hours and as the $\mathrm{pH}$ increases, the amount of the drug dissolved from the $\gamma$-CD-MOFs was $10-17 \%$ after the first $30 \mathrm{~min}$, increasing to $35-40 \%$ after $4 \mathrm{~h}$ immersion at $\mathrm{pH} 7.4$; for the $\mathrm{Na}^{+}$and $\mathrm{K}^{+} \gamma$-CD-MOFs, no further release was observed, with a total of $40 \%$ diclofenac sodium dissolved after $24 \mathrm{~h}$ (the total observation time of the assay), while the Fe- $\gamma$-CD-MOF kept releasing diclofenac sodium in a gradual way over the entire length of the assay, that is, $18 \mathrm{~h}$ of immersion at $\mathrm{pH} 6.8$, reaching a dissolution value of c.a. $60 \%$ (Figure 3).

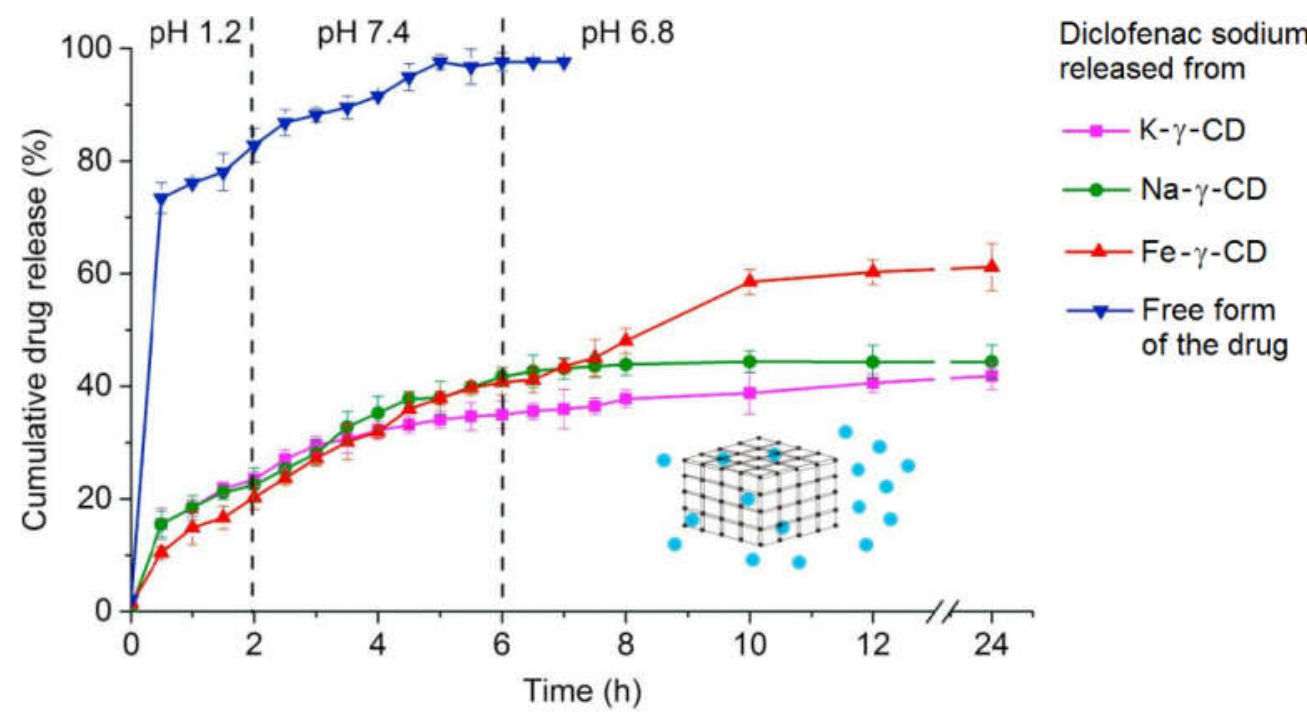

Figure 3. Release rates of diclofenac sodium, either in the free form (blue triangles) or when carried by $\mathrm{K}-\gamma$-CD-MOF (pink squares), Na- $\gamma$-CD-MOF (green dots) and Fe- $\gamma$-CD-MOF (red triangles) in different simulated biological fluids: $\mathrm{HCl} 0.2 \mathrm{M}(\mathrm{pH} 1.2)$ to simulate the gastric fluid, phosphate buffer solution (PBS) at $\mathrm{pH} 7.4$ to simulate the intestinal fluid and $\mathrm{PBS}$ at $\mathrm{pH} 6.8$ to simulate the colonic fluid. Reproduced with permission from Abuçafy et al. [38].

In vivo studies using the carrageenan-induced paw edema model in mice further confirmed that the anti-inflammatory activity of sodium diclofenac when carried by the Fe- $\gamma$-CD-MOF (88.7\% effectiveness) was quite superior to that of the pure drug $(30.4 \%$ effectiveness) and to those obtained with the other two $\gamma$-CD-MOF carriers $(17.3 \%$ and $26.8 \%)$ [38].

Ibuprofen, one of the most widely used NSAIDs, was loaded into the $\gamma$-CD-MOF with $\mathrm{K}^{+}$and the product was evaluated regarding oral bioavailability in mice [39]. The most significant alteration in comparison with the profile of the drug was an increase in the plasma half-life, from $1.07 \pm 0.29 \mathrm{~h}$ (plain ibuprofen potassium salt) to $2.35 \pm 0.68$ for the $\gamma$-CD-MOF loaded with ibuprofen. The $\gamma$-CD-MOF was thus an adequate delivery vehicle for extending the duration of the analgesic and anti-inflammatory effects of ibuprofen. $\gamma$-CD-MOFs with $\mathrm{K}^{+}$metal centres were further demonstrated to suitably load ketoprofen and fenbufen, [24] but release profile and pharmacokinetics were not evaluated.

An overview of the reported $\gamma$-CD-MOF delivery systems with arthritis-relevant NSAIDs is presented in Table 1; drug structures are in Figure 4. 
Table 1. Overview of literature pharmacologic data on NSAID-loaded $\gamma$-CD-MOF systems.

\begin{tabular}{|c|c|c|c|c|}
\hline Guest Drug & Carrier & $\begin{array}{c}\text { In Vivo Studies-GI Tract } \\
\text { Model }\end{array}$ & In Vivo Studies & Ref. \\
\hline Diclofenac sodium & $\mathrm{Na}-\gamma-\mathrm{CD}-\mathrm{MOF}$ & $\begin{array}{l}\text { Sustained release profile } \\
40 \% \text { drug release at } 24 \mathrm{~h}\end{array}$ & $\begin{array}{l}\text { Anti-inflammatory action } \\
\text { slightly lower than pure drug }\end{array}$ & [38] \\
\hline Diclofenac sodium & $\mathrm{K}-\gamma-\mathrm{CD}-\mathrm{MOF}$ & $\begin{array}{l}\text { Sustained release profile } \\
40 \% \text { drug release at } 24 \mathrm{~h}\end{array}$ & $\begin{array}{l}\text { Anti-inflammatory action } \\
\text { similar to pure drug }\end{array}$ & [38] \\
\hline Diclofenac sodium & $\mathrm{Na}-\gamma-\mathrm{CD}-\mathrm{MOF}$ & $\begin{array}{l}\text { Sustained release profile } \\
60 \% \text { drug release at } 24 \mathrm{~h}\end{array}$ & $\begin{array}{l}\text { Three-fold increase in } \\
\text { anti-inflammatory action }\end{array}$ & [38] \\
\hline Ibuprofen potassium & $\mathrm{K}-\gamma-\mathrm{CD}-\mathrm{MOF}$ & $=0$ & $\begin{array}{l}\text { Two-fold increase of serum } \\
\text { half-life (given per orum) }\end{array}$ & [39] \\
\hline Ketoprofen & $\mathrm{K}-\gamma-\mathrm{CD}-\mathrm{MOF}$ & - & -1 & [24] \\
\hline Fenbufen & $\mathrm{K}-\gamma-\mathrm{CD}-\mathrm{MOF}$ & - & - & [24] \\
\hline
\end{tabular}<smiles>[NH2+]C(=O)Cc1ccccc1Nc1c(Cl)cccc1Cl</smiles>

diclofenac sodium<smiles>O=C(O)CCC(=O)c1ccc(-c2ccccc2)cc1</smiles>

fenbufen<smiles>CC(C)Cc1ccc(C(C)C(=O)O[Na])cc1</smiles>

ibuprofen (potassium salt)<smiles>CC(C(=O)O)c1cccc(C(=O)c2ccccc2)c1</smiles>

ketoprofen

Figure 4. Overview of the non-steroidal anti-inflammatory drugs (NSAIDs) that have been successfully loaded into $\gamma$-CD-MOFs.

\section{2. $\gamma$-CD-MOFs Stabilised into Cross-Linked Materials and Their Application in Periosteum Bone}

\subsubsection{Preparation and Early Biological Evaluation}

The relatively high aqueous solubility of the components of $\gamma-\mathrm{CD}-\mathrm{MOF}$ makes them susceptible of some degree of disintegration in aqueous media [40]. To avoid this fragility, researchers have sought methods of stabilising the structure of $\gamma$-CD-MOFs. The use of a cross-linking agent for the $\gamma$-CD molecules affords the desired effect, as it generates an insoluble gel that is able to incorporate water and to have some degree of swelling upon hydration while retaining the cubic shape of the MOF crystallites.

The first cross-linked $\gamma$-CD-MOF-derived material was prepared using the $\gamma$-CD-MOF with $\mathrm{K}^{+}$as the metal centre as a starting material and ethylene glycol diglycidyl ether as the cross-linking agent (Figure 5) [41]. 


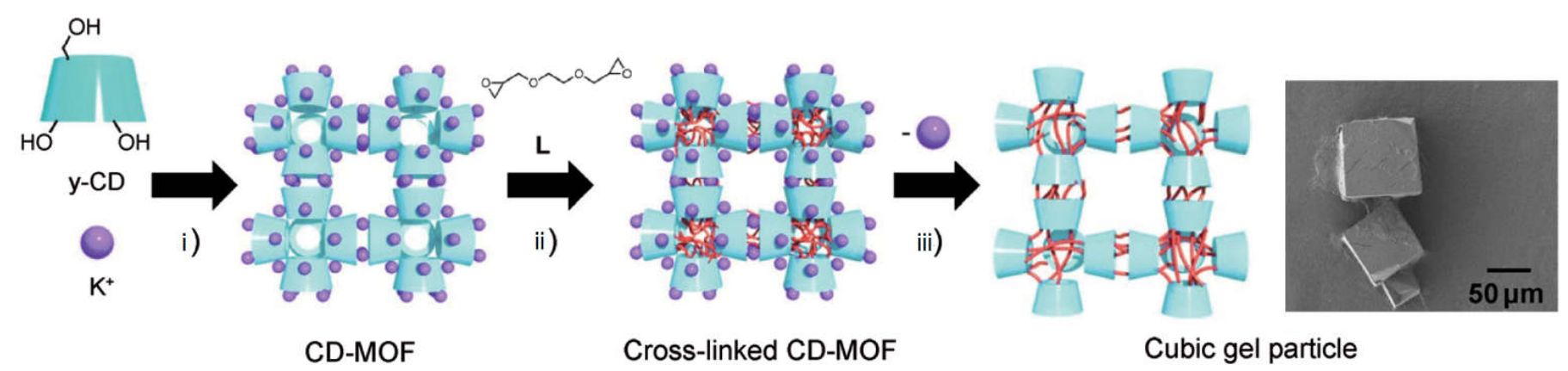

Figure 5. Overview of the preparation steps for the $\mathrm{K}^{+}-\gamma-\mathrm{CD}-\mathrm{MOF}$ and its derived cubic-shaped gel: (i) the MOF is prepared from $\mathrm{K}^{+}$and $\gamma$-CD by crystallisation; (ii) $\gamma$-CD-MOF crystals are treated with the cross-linking agent $(\mathrm{L})$; (iii) $\mathrm{K}^{+}$ions are removed to obtain the gel particles, which retain the cubic shape as demonstrated by its SEM image (right). Reprinted with permission from Furukawa et al. [41].

In a first step, the $\gamma$-CD-MOF was immersed in an ethanol solution of the cross-linking agent and kept for three days at $65{ }^{\circ} \mathrm{C}$ to allow the two epoxy groups to crosslink between the hydroxyl groups of $\gamma$-CD molecules. Following, a washing step removed the $\mathrm{K}^{+}$ions. The resulting cubic gel particles retained the geometry of $\gamma-\mathrm{CD}$ units from its parent $\mathrm{K}-\gamma$-CD-MOF [41].

The safety and biocompatibility of $\gamma$-CD-MOF-derived gels has only very recently begun to be explored. The first of these reports, dating from early 2021, described the preparation of gels from crystals of $\gamma$-CD-MOF by crosslinking them with diphenyl carbonate. The resulting gel retained the cubic shape of the templating $\gamma$-CD-MOF crystals, yielding particles with a mean size of $150 \mathrm{~nm}$. Biodistribution and biocompatibility were evaluated in vivo on C57BL/ 6 mice after intravenous administration in the tail vein. Biodistribution, measured $3 \mathrm{~h}$ after administration using an in vivo imaging system, showed higher accumulation in the lungs (which led the authors to propose using the cross-linked $\gamma$-CD gel as a lung-targeting system). Some accumulation in the liver was observed, and only trace amounts were found in the heart, spleen and kidney. Post-sacrificial histopathologic analysis of mouse heart, liver, spleen and kidney tissue revealed no indicators of normal tissue damage or adverse hematologic effects, thus indicating good biocompatibility [42].

\subsubsection{Application to Periosteum Bone}

A recent work on the application of $\gamma$-CD-MOF-derived gel particles employed diphenyl carbonate as the crosslinking agent. This linker formed short-chained carbonate bridges between the units of $\gamma$-CD (Figure 6). Note that, to speed up the reaction process, triethylamine (TEA) was added as a catalyst, allowing the crosslinking reaction to be achieved in as little as $4 \mathrm{~h}$ [43]. While expected to have a lower ability of swelling because of the tight linking units, this process is advantageous because the preparation time of the gel is greatly reduced (from the three days reported by Furukawa et al. [41] to a few hours). 


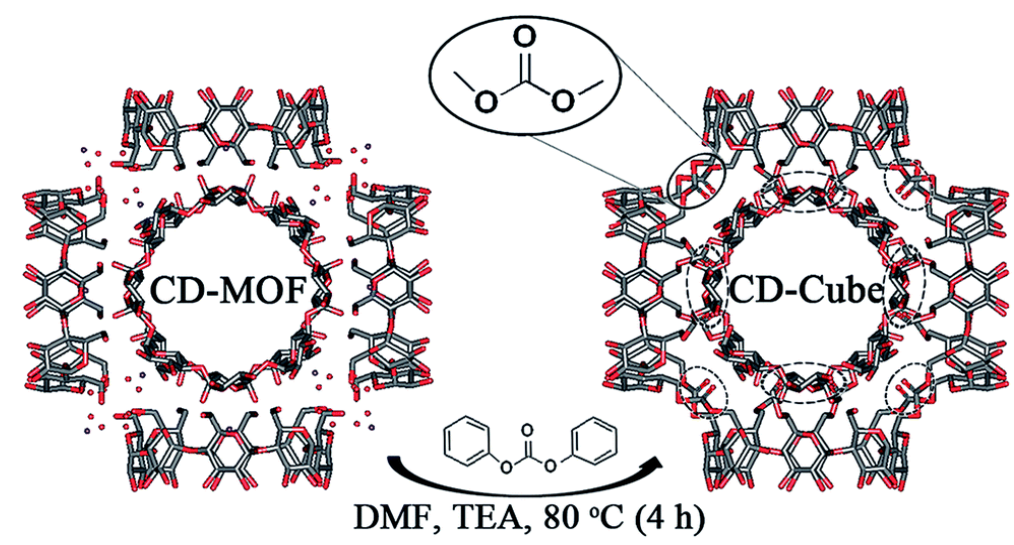

Figure 6. Reaction conditions and structural representation of the formation of a cross-linked cubic gel starting from $\gamma$-CD-MOF, depicted for one of its $(\gamma-C D)_{6}$ cubic units and highlighting the kind of chemical links formed. Reproduced from Singh et al. [43] under a Creative Commons Attribution 3.0 Unported Licence (2017).

The cross-linked cubic gel was loaded with iodine by immersion into a solution of $\mathrm{KI}_{3}$ for $2 \mathrm{~h}$, affording a load of c.a. $30 \%(w / w)$. The particles of the gel were observed by SEM to show that, as expected, they did not significantly increase in size with the loading process, remaining within 5-20 $\mu \mathrm{m}$ and having an average size of $11.8 \mu \mathrm{m}$. Envisioning application of the gel as a carrier for local delivery in the buccal cavity, its release properties were studied in vitro using artificial saliva. Results showed that roughly half of the load in iodine was released in the first $12 \mathrm{~h}$ of immersion, followed by a period with practically no further iodine release. The therapeutic effect in vivo was evaluated in rats using a periodontitis model, comparing the iodine-loaded gel with a model drug, minocycline. Both the gel and minocycline were administered every three days for a total period of four weeks, and both showed similar results in the symptomatic relief of periodontitis. Histological examination of the periodontium confirmed these results: in contrast with non-treated rats, which exhibited a large number of infiltrating inflammatory cells and osteolytic osteoclast cells into the bone tissue, the tissue of rats treated with iodine-loaded gel or with a minocycline ointment revealed a low number of infiltrated inflammatory cells, meaning that both treatments were able to reduce tissue inflammation. In addition, the connective tissue arrangement was returned to normal, with lack of osteoclasts in the periosteum and osteoblasts being observed instead (Figure 7). These histological changes signified that following the four-week treatment with minocycline or with iodine-loaded gel the morphology of periodontal gingival tissue was restored to that which is typically observed in the healthy rat [44]. 

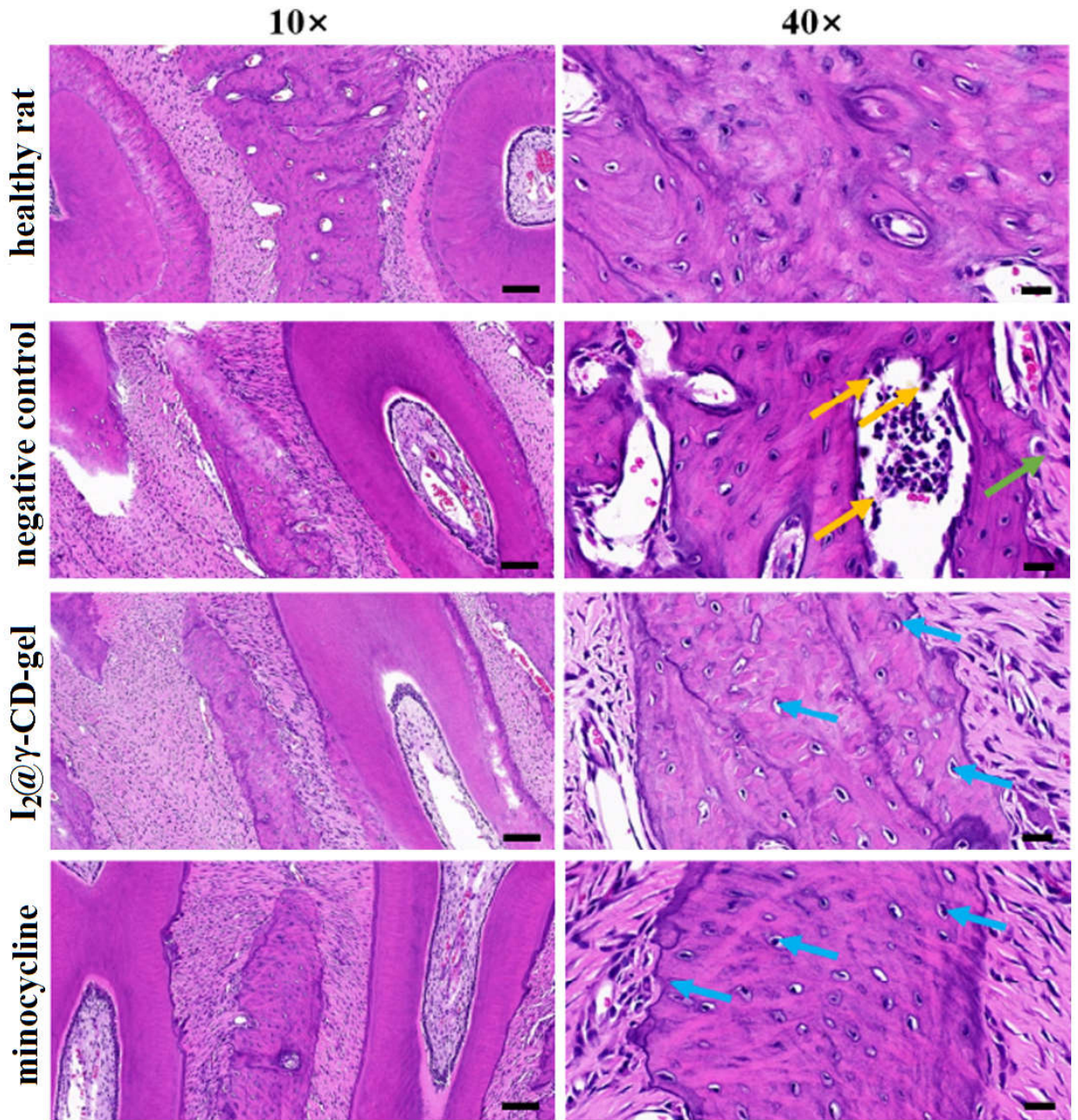

Figure 7. Histology of the left upper jaw of rats in the normal periodontium (upper line), periodontitisinduced (negative control, second line from the top), minocycline treatment group (third line), and the group treated with iodine-loaded gel $\left(\mathrm{I}_{2} @ \gamma-\mathrm{CD}\right.$-gel, bottom line). Samples were stained using the H\&E (hematoxylin and eosin) dye mixture. Green, blue and orange arrows represent infiltrated inflammatory cells, osteoblasts and osteoclasts, respectively. Scale bar represents $100 \mu \mathrm{m}, 20 \mu \mathrm{m}$ for $10 \times, 40 \times$, respectively. Reprinted with permission from Lu et al. [44] (Copyright 2021, Elsevier Ltd.).

\section{Overview and Future Outlook}

Metal-Organic Frameworks have been gaining interest as drug delivery vehicles because of their high loading ability and the flexibility of construction to obtain biocompatible and biodegradable materials. The use of cyclodextrins, either as building blocks or in coatings on the particles of these materials, is a strategy developed over the last two decades that contributes to ensure better biocompatibility and to a sustained release $[31,38,39,44]$.

Delivery of active pharmaceutical ingredients for ostheotherapeutics is an emerging, niche application for MOFs. The literature herein described and summarised present several promising development routes. Coating of MIL-88B with $\beta-C D$ afforded a material able to release alendronate for as long as four weeks [31], which opens the possibility of a monthly treatment for osteoporosis, for instance, using this system as an in vivo depot. Before this or other clinical applications come to light, further studies are needed to ensure in vivo safety and degradability of MIL-88B with $\beta$-CD.

MOFs built with $\gamma$-CD were shown, in several studies, to be good carriers for nonsteroidal anti-inflamatory drugs. With diclofenac sodium, a sustained release was observed for up to $24 \mathrm{~h}$ in aqueous media simulating the gastro-intestinal track. Highlight goes to the non-conventional $\gamma$-CD-MOF built with iron metal centres which was further shown to 
increase in vivo effectiveness of diclofenac sodium by almost three-fold when compared with that of the pure drug on the mouse paw edema model for inflammation [38]. Given the known safety of the carrier material [18,19], this strategy offers the possibility of reducing the dosage of NSAIDS for osteoarthritis patients without compromising the activity. This will be extremely beneficial given the gastrointestinal and haematological side effects of the high dosages typically associated with this condition. So far, the potentiating effect has only been demonstrated for mice. Thus, clinical trials on human patients are needed to confirm its applicability in our species.

Successful application of $\gamma$-CD-MOFs in periosteal bone, i.e., inside the buccal cavity, was achieved by generating cross-linked derivatives that do not degrade in aqueous media. One of these gels, when loaded with the biocidal iodine, showed equivalent activity to the antibiotic drug minocycline and contributed to bone tissue regeneration [44] These results are quite exciting as they open way for application in the repair of bone fractures. The qualitative step towards application in an internal tissue still requires further development: the material should have a nanometric particle size to ensure haematological compatibility and it should degrade slowly enough to afford a sustained release of the therapeutic agents. These can comprise, for instance, a combination of steroidal drugs, for inflammation mitigation, and bisphosphonates, for bone growth promotion. The material cannot, however, be completely non-degradable because one has to ensure that it will, over a few weeks, be reabsorbed by the organism and give way to osteoblast migration and the growth of new bone at the fracture site. This can be achieved by a careful choice of the reaction conditions and of the cross-linking agent, giving preference to the formation of chemical bonds that can be broken down by the lytic vesicles of osteoclastasts.

Author Contributions: This article was written with equal contribution of both authors. All authors have read and agreed to the published version of the manuscript.

Funding: We acknowledge University of Aveiro and FCT/MCTES (Fundação para a Ciência e a Tecnologia, Ministério da Ciência, da Tecnologia e do Ensino Superior) for financial support to LAQV-REQUIMTE (Ref. UIDB/50006/2020) and to CICECO-Aveiro Institute of Materials (Refs. UIDB/50011/2020 \& UIDP/50011/2020) through national founds and, where applicable, co-financed by the FEDER, within the PT2020 Partnership Agreement.

Conflicts of Interest: The authors declare no conflict of interest.

$\begin{array}{ll}\text { Abbreviations } \\ \text { API } & \text { Active Pharmaceutical Ingredient } \\ \text { DMF } & \text { Dimethylformamide } \\ \text { EMA } & \text { European Medicines Agency } \\ \text { FAO } & \text { Food and Agriculture Organisation } \\ \text { GI } & \text { Gastro-Intestinal } \\ \text { GRAS } & \text { Generally Regarded as Safe } \\ \gamma \text {-CD } & \text { Gamma-Cyclodextrin } \\ \text { JECFA } & \text { Joint FAO/WHO Expert Committee on Food Additives } \\ \text { HP } \beta C D & \text { (2-Hydroxy)propyl-beta-cyclodextrin } \\ \text { HP } \gamma \text { CD } & \text { (2-Hydroxy)propyl-gamma-cyclodextrin } \\ \text { MIL } & \text { Materiaux de l'Institut Lavoisier } \\ \text { MOF } & \text { Metal-Organic Framework } \\ \text { NSAID } & \text { Non-Steroidal Anti-Inflammatory Drug } \\ \text { SEM } & \text { Scanning electron microscopy } \\ \text { TEA } & \text { Triethylamine } \\ \text { WHO } & \text { World Health Organisation }\end{array}$




\section{References}

1. Carreon, M.A.; Venna, S.R. Metal Organic Frameworks History and Structural Features. In Metal-Organic Framework Membranes for Molecular Gas Separations, 1st ed.; World Scientific Publishing Europe Ltd.: Singapore, 2020; Chapter 1, pp. 1-29. [CrossRef]

2. Tomic, E.A. Thermal stability of coordination polymers. J. Appl. Polym. Sci. 1965, 9, 3745-3752. [CrossRef]

3. Pascanu, V.; Miera, G.G.; Inge, A.K.; Martín-Matute, B. Metal-organic frameworks as catalysts for organic synthesis: A Critical perspective. J. Am. Chem. Soc. 2019, 141, 7223-7234. [CrossRef] [PubMed]

4. Tran, Y.B.N.; Nguyen, P.T.K.; Luong, Q.T.; Nguyen, K.D. Series of M-MOF-184 (M = Mg, Co, Ni, Zn, Cu, Fe) metal-organic frameworks for catalysis cycloaddition of $\mathrm{CO}_{2}$. Inorg. Chem. 2020, 59, 16747-16759. [CrossRef] [PubMed]

5. Razavi, S.A.A.; Morsali, A. Metal ion detection using luminescent-MOFs: Principles, strategies and roadmap. Coord. Chem. Rev. 2020, 415, 213299. [CrossRef]

6. Li, H.Y.; Zhao, S.N.; Zang, S.Q.; Li, J. Functional metal-organic frameworks as effective sensors of gases and volatile compounds. Chem. Soc. Rev. 2020, 49, 6364-6401. [CrossRef]

7. Chen, L.D.W.; Zhu, P.; Tian, Y.; Chen, Y.; Wu, C. Applications of Functional Metal-Organic Frameworks in Biosensors. Biotechnol. J. 2020, 16, 1900424. [CrossRef]

8. $\quad$ Figueira, F.; Barbosa, J.S.; Mendes, R.F.; Braga, S.S.; Paz, F.A.A. Virus meet metal-organic frameworks: A nanoporous solution to a world-sized problem? Mater. Today 2021, 43, 84-98. [CrossRef]

9. McKinlay, A.C.; Morris, R.E.; Horcajada, P.; Férey, G.; Gref, R.; Couvreur, P.; Serre, C. BioMOFs: Metal-organic frameworks for biological and medical applications. Angew. Chem. Int. Ed. 2010, 49, 6260-6266. [CrossRef]

10. Vassaki, M.; Papathanasiou, K.E.; Hadjicharalambous, C.; Chandrinou, D.; Turhanen, P.; Choquesillo-Lazarte, D.; Demadis, K.D. Self-sacrificial MOFs for ultra-long controlled release of bisphosphonate anti-osteoporotic drugs. Chem. Commun. 2020, 56, 5166-5169. [CrossRef]

11. Smaldone, R.A.; Forgan, R.S.; Furukawa, H.; Gassensmith, J.J.; Slawin, A.M.Z.; Yaghi, O.M.; Stoddart, J.F. Metal-organic frameworks from edible natural products. Angew. Chem. Int. Ed. 2010, 49, 1-6. [CrossRef]

12. Rincón-López, J.; Almanza-Arjona, Y.C.; Riascos, A.P.; Rojas-Aguirrea, Y. Technological evolution of cyclodextrins in the pharmaceutical field. J. Drug Deliv. Sci. Technol. 2021, 61, 102156. [CrossRef] [PubMed]

13. Aiassa, Z.; Garnero, C.; Longhi, M.R.; Zoppi, A. Cyclodextrin multicomponent complexes: Pharmaceutical applications. Pharmaceutics 2021, 13, 1099. [CrossRef] [PubMed]

14. Braga, S.S.; Pais, J. Getting under the skin: Cyclodextrin inclusion for the controlled delivery of active substances to the dermis. In Design of Nanostructures for Versatile Therapeutic Applications, 1st ed.; Grumezescu, A., Ed.; Elsevier: Amsterdam, The Netherlands, 2018; Chapter 10; pp. 407-449. [CrossRef]

15. Pereira, A.B.; Braga, S.S. Cyclodextrin Inclusion of Nutraceuticals, from the Bench to your Table. In Cyclodextrins: Synthesis, Chemical Applications and Role in Drug Delivery, 1st ed.; Ramirez, F.G., Ed.; NovaSience: Hauppage, NY, USA, 2015; Chapter 6, pp. 195-224, ISBN 978-1-63482-788-1.

16. Agency Response Letter Gras Notice GRN, No. 155; Office of Food Additive Safety, Center for Food Safety and Applied Nutrition, US Food and Drug Administration: College Park, MD, USA, 2004.

17. Agency Response Letter Gras Notice GRN, No. 74; Office of Food Additive Safety, Center for Food Safety and Applied Nutrition, US Food and Drug Administration: Washington, DC, USA, 2001.

18. Agency Response Letter Gras Notice GRN, No. 46; Office of Food Additive Safety, Center for Food Safety and Applied Nutrition, US Food and Drug Administration: Washington, DC, USA, 2000.

19. European Medicines Agency. Background Review for Cyclodextrins Used as Excipients; EMA: London, UK, 2014. Available online: http:/ / www.ema.europa.eu/docs/en_GB/document_library/Report/2014/12/WC500177936.pdf (accessed on 8 February 2021).

20. Kroes, R.; Verger, P.; Larsen, J.C. Safety evaluation of certain food additives ( $\alpha$-cyclodextrin-Addendum). WHO Food Addit. Ser. 2006, 54, 3-15.

21. Pollit, F.D. Safety evaluation of certain food additives ( $\beta$-cyclodextrin). WHO Food Addit. Ser. 1996, 35, $257-268$.

22. Abbott, P.J. JEFCA 55th meeting: Safety evaluation of certain food additives and contaminants ( $\gamma$-cyclodextrin). WHO Food Addit. Ser. 2000, 44, 969.

23. Li, X.; Guo, T.; Lachmanski, L.; Manoli, F.; Menendez-Miranda, M.; Manet, I.; Guo, Z.; Wu, L.; Zhang, J.; Gref, R. Cyclodextrinbased metal-organic frameworks particles as efficient carriers for lansoprazole: Study of morphology and chemical composition of individual particles. Int. J. Pharm. 2017, 513, 424-432. [CrossRef]

24. Xu, X.; Wang, C.; Li, H.; Li, X.; Liu, B.; Singh, V.; Wang, S.; Sun, L.; Gref, R.; Zhang, J. Evaluation of drug loading capabilities of $\gamma$-cyclodextrin-metal organic frameworks by high performance liquid chromatography. J. Chromatogr. A 2017, 1488, 37-44. [CrossRef]

25. Chen, Y.; Tai, K.; Ma, P.; Su, J.; Dong, W.; Gao, Y.; Mao, L.; Liu, J.; Yuan, F. Novel $\gamma$-cyclodextrin-metal-organic frameworks for encapsulation of curcumin with improved loading capacity, physicochemical stability and controlled release properties. Food Chem. 2021, 347, 128978. [CrossRef]

26. Xu, J.; Wu, L.; Guo, T.; Zhang, G.; Wang, C.; Li, H.; Li, X.; Singh, V.; Chen, W.; Gref, R.; et al. A “Ship-in-a-Bottle" strategy to create folic acid nanoclusters inside the nanocages of $\gamma$-cyclodextrin metal-organic frameworks. Int. J. Pharm. 2019, 556, 89-96. [CrossRef] 
27. Surble, S.; Serre, C.; Mellot-Draznieks, C.; Millange, F.; Férey, G. A new isoreticular class of metal-organic-frameworks with the MIL-88 topology. Chem. Commun. 2006, 284-286. [CrossRef]

28. Huynh, N.T.X.; Chihaia, V.; Son, D.N. Hydrogen storage in MIL-88 series. J. Mater. Sci. 2018, 54, 3994-4010. [CrossRef]

29. Barbosa, J.S.; Figueira, F.; Braga, S.S.; Paz, F.A.A. Metal-organic frameworks for biomedical applications: The case of functional ligands. In Metal-Organic Frameworks for Biomedical Applications, 1st ed.; Mozafari, M., Ed.; Woodhead Publishing: Cambridge, UK; Elsevier: Duxford, UK, 2020; Chapter 4; pp. 69-92. [CrossRef]

30. Agostoni, V.; Horcajada, P.; Noiray, M.; Malanga, M.; Aykaç, A.; Jicsinszky, L.; Vargas-Berenguel, A.; Semiramoth, N.; DaoudMahammed, S.; Nicolas, V.; et al. A "green" strategy to construct non-covalent, stable and bioactive coatings on porous MOF nanoparticles. Sci. Rep. 2014, 5, 7925. [CrossRef] [PubMed]

31. Golmohamadpour, A.; Bahramian, B.; Shafiee, A.; Ma'mani, L. Slow released delivery of alendronate using $\beta$-cyclodextrine modified Fe-MOF encapsulated porous hydroxyapatite. J. Inorg. Organomet. Polym. Mat. 2018, 28, 1991-2000. [CrossRef]

32. Forgan, R.S.; Smaldone, R.A.; Gassensmith, J.J.; Furukawa, H.; Cordes, D.B.; Li, Q.; Wilmer, C.E.; Botros, Y.Y.; Snurr, R.Q.; Slawin, A.M.Z.; et al. Nanoporous carbohydrate metal-organic frameworks. J. Am. Chem. Soc. 2012, 134, 406-417. [CrossRef] [PubMed]

33. Henrotin, Y.; Pesesse, L.; Sanchez, C. Subchondral bone and osteoarthritis: Biological and cellular aspects. Osteoporos. Int. 2012, 23 (Suppl. 8), S847-S851. [CrossRef]

34. Goldring, S.R. The role of bone in osteoarthritis pathogenesis. Rheum. Dis. Clin. N. Am. 2008, 34, 561-571. [CrossRef]

35. Walsh, D.A.; McWilliams, D.F.; Turley, M.J.; Dixon, M.R.; Fransès, R.E.; Mapp, P.I.; Wilson, D. Angiogenesis and nerve growth factor at the osteochondral junction in rheumatoid arthritis and osteoarthritis. Rheumatology 2010, 49, 1852-1861. [CrossRef]

36. Dougados, M. Why and how to use NSAIDs in osteoarthritis. J. Cardiovasc. Pharmacol. 2006, 47, S49-S54. Available online: https:// journals.lww.com/cardiovascularpharm/fulltext/2006/05001/why_and_how_to_use_nsaids_in_osteoarthritis.9.aspx (accessed on 18 November 2021). [CrossRef]

37. Pelletier, J.P.; Martel-Pelletier, J.; Rannou, F.; Cooper, C. Efficacy and safety of oral NSAIDs and analgesics in the management of osteoarthritis: Evidence from real-life setting trials and surveys. Semin. Arthritis Rheum. 2016, 45, S22-S27. [CrossRef]

38. Abuçafy, M.P.; Caetano, B.L.; Chiari-Andréo, B.G.; Fonseca-Santos, B.; Santos, A.M.; Chorilli, M.; Chiavacci, L.A. Supramolecular cyclodextrin-based metal-organic frameworks as efficient carrier for anti-inflammatory drugs. Eur. J. Pharm. Biopharm. 2018, 127, 112-119. [CrossRef]

39. Hartlieb, K.J.; Ferris, D.P.; Holcroft, J.M.; Kandela, I.; Stern, C.L.; Nassar, M.S.; Botros, Y.Y.; Stoddart, J.F. Encapsulation of ibuprofen in CD-MOF and related bioavailability studies. Mol. Pharm. 2017, 14, 1831-3189. [CrossRef] [PubMed]

40. Qiu, J.; Li, X.; Gref, R.; Vargas-Berenguel, A. Carbohydrates in metal organic frameworks: Supramolecular assembly and surface modification for biomedical applications. In Metal-Organic Frameworks for Biomedical Applications, 1st ed.; Mozafari, M., Ed.; Woodhead Publishing: Cambridge, UK; Elsevier: Duxford, UK, 2020; Chapter 20; pp. 445-465. [CrossRef]

41. Furukawa, Y.; Ishiwata, T.; Sugikawa, K.; Kokado, K.; Sada, K. Nano- and microsized cubic gel particles from cyclodextrin metal-organic frameworks. Angew. Chem. Int. Ed. 2012, 51, 10566-10569. [CrossRef] [PubMed]

42. He, Y.; Xiong, T.; He, S.; Sun, H.; Huang, C.; Ren, X.; Wu, L.; Patterson, L.H.; Zhang, J. Pulmonary Targeting Crosslinked Cyclodextrin Metal-Organic Frameworks for Lung Cancer Therapy. Adv. Funct. Mater. 2021, 31, 2004550. [CrossRef]

43. Singh, V.; Guo, T.; Wu, L.; Xu, J.; Liu, B.; Gref, R.; Zhang, J. Template-directed synthesis of a cubic cyclodextrin polymer with aligned channels and enhanced drug payload. RSC Adv. 2017, 7, 20789-20794. [CrossRef]

44. Lu, S.; Ren, X.; Guo, T.; Cao, Z.; Sun, H.; Huang, C.; Huang, F.; Shu, Z.; Hao, J.; Gui, S.; et al. Controlled release of iodine from cross-linked cyclodextrin metal-organic frameworks for prolonged periodontal pocket therapy. Carbohydr. Polym. 2021, 267, 118187. [CrossRef] [PubMed] 